\title{
Вопросы оценки стоимости добывающей компании
}

А.А. БАЛАБИН, кандидат экономических наук, Институт экономики и организации промышленного производства СО РАН, Новосибирский государственный технический университет. E-mail: balabin-a-a@mail.ru

В.А. ЩЕРБАКОВ, кандидат экономических наук, Сибирский государственный университет путей сообщения. E-mail: serbakov@ngs.ru

Н.А. ЩЕРБАКОВА, кандидат экономических наук, Новосибирский государственный технический университет. E-mail: serbakova.n@gmail.com

В статье рассматриваются подходы к оценке фундаментальной стоимости крупных российских добывающих компаний для цели их приватизации. Приводятся особенности применения традиционных стандартов оценки бизнеса, демонстрируются их недостатки применительно к добывающим компаниям. Оцениваются возможности использования различных методик в современной экономической ситуации, выделяются наиболее предпочтительные. Получение точной аналитической оценки фундаментальной стоимости добывающей компании сталкивается с серьёзными трудностями, что делает необходимым применение современных рыночных способов приватизации.

Ключевые слова: оценка стоимости бизнеса, добывающая компания, приватизация, фундаментальная стоимость компании, «Роснефть»

Наверное, никто не станет спорить, что добывающие отрасли (нефтяная, газовая, угольная, горно-металлургическая и т.п.) являются весомой частью российской экономики. И останутся ею в обозримом будущем, несмотря на усилия по реиндустриализации страны, восстановлению отдельных обрабатывающих производств и созданию новых инновационных направлений деятельности.

В сегодняшнюю повестку дня вновь внесен вопрос о частичной приватизации некоторых крупных предприятий (в том числе и в сырьевом секторе) для пополнения федерального бюджета в условиях кризиса. Речь идет об ОАО НК «Роснефть» (далее «Роснефть»), ПАО АНК «Башнефть», АК «Алроса» (ПАО). При этом «все приватизационные сделки должны строго соответствовать нормам и требованиям закона... Необходимо обеспечить и максимальную прозрачность этих сделок как для их участников, так и для общественности... Не должно быть продаж акций за бесценок, по бросовой цене» [1].

Давайте посмотрим, какие нормы и требования закона по оценке бизнеса в нашей стране введены в настоящее время, и как они действуют применительно к добывающим компаниям. 
Казалось бы, это достаточно проработанная в научном отношении тема [2-6]. Создано базовое законодательство в этой сфере [7-9]. Целое направление российского бизнеса занимается оценочной деятельностью, есть и международные авторитеты в этой области ${ }^{1}$. Но всякий раз, когда речь заходит об изменениях в составе собственников сколько-нибудь значимой добывающей компании или её части (не говоря уж о приватизации), разгораются страсти. Снова и снова ставится вопрос - а насколько справедлива полученная оценка, не продешевил ли продавец, и не получил ли необоснованной выгоды покупатель.

\section{Недостатки методик...}

Профессиональные оценщики, основываясь на федеральных стандартах [7, раздел III], обязаны проанализировать три подхода к оценке объекта - сравнительный, доходный и затратный. При выборе используемых в конкретной ситуации подходов оценщик должен учесть их возможности, цели и задачи оценки, предполагаемое применение ее результатов, допущения, полноту и достоверность исходной информации.

Рассмотрим сравнительный подход, который рекомендуется применять, когда доступна достоверная и достаточная для анализа информация о характеристиках и ценах объектов-аналогов (как по совершённым сделкам, так и по предложениям о покупке-продаже). Аналог бывает нелегко найти даже для автозаправки или квартиры, и почти невозможно это сделать для наиболее крупных компаний. Например, если оцениваются акции «Роснефти», нужно найти какую-либо похожую на нее компанию, которую продавали в недавнем прошлом при схожих обстоятельствах. Для компании, входящей в число крупнейших в мире ${ }^{2}$, это маловероятно.

1 Общий объем рынка оценочных услуг в России в 2014 г. оценивался в 9,8 млрд руб. (данные RAEX («Эксперт PA»). URL: http://raexpert.ru/ratings/ appraising_potential/2014 (дата обращения: 20.02.2016). В области оценки сырьевых компаний широкую известность в России получила работа компаний Morgan Stanley, Dresdner Kleinwort Wasserstein и российской «2K Аудит - Деловые консультации» в связи с оценкой и последующей продажей крупного пакета акций ОАО «Газпром» в 2005 г.

${ }^{2}$ В настоящее время «Роснефть» занимает 15-е место в мире по добыче энергетического сырья (по версии журнала Forbs). URL: http://m.forbes.ru/ article.php?id=84318, (дата обращения: 07.04.2016). 
Не спасает и то, что акции некоторых публичных добывающих компаний (например, той же «Роснефти») торгуются на фондовых биржах. Казалось бы, проще простого вычислить рыночную капитализацию (умножив количество выпущенных акций на их текущую биржевую цену) - и вот вам настоящая, самая рыночная из рыночных оценка бизнеса. Однако это не так.

Во-первых, как показывает практика, рыночная капитализация весьма изменчива, она следует за спекулятивными трендами рынка ценных бумаг. Так, в течение 2013-2014 гг. цена на акции «Роснефти» менялась от 178,92 до 275,50 руб./шт. ${ }^{3}$ Разброс цен (и, соответственно, размах величины рыночной капитализации) составил 53,6\%. За тот же период прибыль до уплаты налогов, процентов и амортизации (EBITDA) изменилась с 947 до 1057 млрд руб. ${ }^{4}$ А значит, если бы мы измеряли стоимость «Роснефти», используя для расчета потока платежей EBITDA, то эта стоимость (при неизменности прочих допущений) изменилась бы приблизительно на $12 \%$.

Во-вторых, в биржевую торговлю вовлекаются далеко не все выпущенные акции. В частности, у «Роснефти» в третьем квартале 2014 г. доля акций в свободном обращении составляла $12 \%$ [10. С. 106], а среднедневной биржевой оборот не превосходил $0,25 \%$ от общего количества выпущенных акций.

Конечно, в рамках технического анализа биржевого рынка ценных бумаг существуют всевозможные изощренные методы сглаживания динамических рядов цен и их прогнозирования. Но факт остается фактом - предсказать достоверно движение цены и уж тем более указать на некую, отличную от текущей рыночной, «справедливую» цену акций не удаётся.

По сути, стоимость стабильно функционирующей компании (каковой является и «Роснефть») должна представлять собой некую величину, не зависящую от краткосрочных спекулятивных действий участников фондового рынка. Следовательно,

\footnotetext{
${ }^{3}$ Использовались ежедневные данные о максимальной и минимальной ценахна обыкновенные акции «Роснефти» по итогам торгов на Московской бирже. URL: http://www.finam.ru/profile/moex-akcii/rosneft (дата обращения: 05.03.2016).

${ }^{4}$ Рассчитано по данным Годового отчета ОАО «НК «Роснефть» за 2014 г. C. 26. URL: www.rosneft.ru/attach/0/02/01/a_report_2014.pdf (дата обращения: 22.02.2016).
} 
прямолинейное применение текущих биржевых оценок (в рамках сравнительного подхода) дает лишь слабый ориентир, но никак не искомую величину фундаментальной стоимости добывающей компании.

В наибольшей мере соответствует сущности бизнеса доходный подход - совокупность методов, основанных на определении ожидаемых доходов от использования объекта оценки. Его рекомендуется применять при наличии достоверной информации, позволяющей прогнозировать будущие доходы, которые объект способен приносить, а также связанные с объектом оценки расходы. В рамках доходного подхода применяются различные методы, основанные на дисконтировании денежных потоков и капитализации дохода.

При внешней простоте и общеизвестности формул оценки (см, например [6. С. 103-106]) наблюдаются значительные методические разночтения в трактовке самого состава показателей, которые нужно включать в денежные потоки предприятия ${ }^{5}$. Кроме того, при практическом применении методик мы сталкиваемся с задачей прогнозирования денежных потоков или же доходов на ближайшие несколько лет. Потоки зависят от цен на производимую продукцию и объемов ее выпуска.

Задача становится весьма сложной применительно к добывающим компаниям, которые действуют в ситуации высокой изменчивости цен на сырье, малопредсказуемых изменений курсов иностранных валют, макроэкономических и внешнеполитических рисков. К примеру, для оценки «Роснефти» доходным подходом нужно уверенно сказать, какими будут цена и объем сбыта нефти, добываемой этой компанией, на пять лет вперед.

Рассмотрим еще один подход к оценке - затратный, основанный на определении стоимости активов и обязательств компании. Согласно стандартам [8] «применение затратного подхода носит ограниченный характер, и данный подход, как правило, применяется, когда прибыль и (или) денежный поток не могут

\footnotetext{
${ }^{5}$ Например, Т. Коупленд, Т. Коллер и Дж. Муррин [5] для целей оценки предполагают, что все денежные потоки предприятия могут быть распределены между акционерами (инвесторами), а Д. Абрамс [2] считает, что учитывать нужно только ту часть денежных потоков, которая не участвует в формировании так называемого «требуемого оборотного капитала».
} 
быть достоверно определены, но при этом доступна достоверная информация об активах и обязательствах организации, ведущей бизнес». Активы добывающих компаний носят преимущественно специализированный характер, и для их оценки часто единственно возможным является затратный подход. В его рамках применяются различные методы, основанные на определении затрат на создание точной копии объекта оценки или объекта, имеющего аналогичные полезные свойства. Но добывающая компания разрабатывает невозобновляемые ресурсы, а каждое месторождение уникально. Поэтому в ходе оценивания можно говорить (и то - условно) лишь о замещении оцениваемого актива.

Соответственно, оценка стоимости добывающей компании затратным методом сильно «плавает» в зависимости от наличия и непрерывности пополнения доступных ей запасов ископаемых. В условиях, когда значительная часть недр суши и морского шельфа остается недостаточно изученной, а геологоразведочные работы идут вяло или вовсе не проводятся, подобные оценки неизбежно становятся неопределенными величинами. Иначе говоря, оценка стоимости затратным подходом для добывающей компании зависит от того, какими ресурсами и производственными мощностями она располагает не только сейчас, но и в будущем. Однако, согласно классическим методикам, результат оценки бизнеса затратным подходом статичен и не учитывает прогнозной динамики активов.

Вообще важнейшей предпосылкой справедливой оценки любой организации является презумпция непрерывности её деятельности. Её отчетность составляется на основании допущения о том, что организация осуществляет свою деятельность непрерывно и продолжит осуществлять ее в обозримом будущем [11. П. 4.1]. В соответствии со стандартом, утвержденным Приказом МЭР [8. П. 11.1], при использовании затратного подхода конкретный метод проведения оценки бизнеса применяется с учетом ожиданий относительно перспектив деятельности организации (ее следует рассматривать как действующую или как ликвидируемую).

В связи с тем, что для конкретной добывающей компании в конкретной стране исполнение принципа непрерывности 
деятельности не очевидно, при оценке требуется введение дополнительных допущений.

В нашей стране при использовании любых подходов ситуацию сильно усложняет постоянное изменение правил государственного регулирования добывающих отраслей, в частности бесконечные корректировки ставок таможенных пошлин, акцизов и налога на добычу полезных ископаемых (НДПИ). Так называемый «налоговый маневр» в нефтяном секторе российской экономики проводится чуть ли не каждые два-три года с 19951996 гг. Сначала его цель состояла в стимулировании экспорта, затем в изменении структуры экспорта сырой нефти и продуктов нефтепереработки, с 2013 г. началось обсуждение проблемы перераспределения доходов, получаемых Беларусью от экспорта продуктов переработки российской нефти. Очередной «налоговый маневр» 2014 г. состоял в утверждении графика снижения предельной ставки экспортной пошлины на нефть с 59\% в 2014 г. до $30 \%$ в 2017 г. при одновременном увеличении базовой ставки НДПИ на нефть с 493 руб./т в 2014 г. до 919 руб./т в 2017 г. Также были подняты ставки экспортных пошлин на нефтепродукты и снижены ставки акцизов на моторные топлива [12].

Сейчас вновь готовится корректировка параметров «налогового маневра», о чем сообщил в конце января 2016 г. вице-премьер Правительства России А. Дворкович [13]. Предположительно увеличение ставки НДПИ пройдет по установленному графику, а экспортная пошлина снижаться не будет ${ }^{6}$. Ясно, что при таких обстоятельствах плановые денежные потоки, и, следовательно, оценка стоимости российской нефтяной компании становятся весьма неопределенными величинами.

Представляется, что оценочные методы должны соотноситься с целями оценки стоимости бизнеса. Стоимость бизнеса, полученная затратным подходом, может использоваться прежде всего в качестве критерия эффективности функционирования предприятия, сравнительным - отражает ситуацию на рынке

\footnotetext{
${ }^{6}$ В марте 2016 г. в Минэнерго состоялось рабочее совещание по реформе налогообложения отрасли, в котором приняли участие представители Минфина и крупнейших нефтяных компаний. Из материалов к совещанию виден разнобой мнений на этот счет. Как сказал один из представителей нефтяных компаний: «Мы против любых резких движений в налогообложении. Чтобы можно было планировать деятельность, нужно, чтобы правила игры были стабильными». Цит. по: (14).
} 
(возможно, кратковременную). Действуя в рамках российских стандартов, стоимость бизнеса для целей приватизации лучше всё же определять на основе доходного подхода [15].

\section{... и их умножение}

Однако самое интересное начинается потом, после получения результатов расчетов в рамках трёх перечисленных выше подходов. Тут у оценщика развязаны руки: он вправе самостоятельно определять необходимость применения тех или иных либо сразу нескольких подходов к оценке и конкретных методов в рамках каждого из них, устанавливать дополнительные допущения, связанные с предполагаемым использованием результатов оценки и спецификой объекта оценки [7. П. 24].

Нужно сказать, что любой подход (точнее говоря, конкретная применяемая методика в рамках подхода) даёт вполне определенный и точный, выраженный в рублях и копейках результат. Но это вовсе не означает, что результаты, полученные разными методиками (и основанные на вполне конкретных вычислениях и прогнозах), должны совпадать. Они, как правило, и не совпадают. Более того, на практике, в отчетах об оценке добывающих компаний, они из-за неопределенности исходных предположений, различаются в разы.

При использовании нескольких подходов (а также нескольких методов оценки) в соответствии со стандартом выполняется так называемое согласование результатов оценки [7. П. 25-26]. Процедура согласования чрезвычайно проста. Каждой (исчисленной точнейшим образом на предшествующих 70-100 страницах текста отчета) предварительной оценке приписывается определенный вес, а итоговая оценка бизнеса определяется как взвешенная величина:

$\mathrm{O}=\mathrm{a}_{1} \mathrm{x}_{1}+\mathrm{a}_{2} \mathrm{x}_{2}+\ldots+\mathrm{a}_{\mathrm{n}} \mathrm{x}_{\mathrm{n}}$

где $\mathrm{O}$ - согласованная рыночная стоимость объекта;

$\mathrm{n}$ - количество использованных оценщиком методик расчетов;

$\mathrm{x}_{1}, \mathrm{x}_{2}, \ldots, \mathrm{x}_{\mathrm{n}}$ - предварительные оценки бизнеса, полученные с помощью вышеупомянутых методик;

$a_{1}, a_{2}, \ldots, a_{n}-$ взвешивающие коэффициенты $\left(a_{1}+a_{2}+\ldots+a_{n}=1\right)$.

Обоснование, почему выбраны те или другие весовые коэффициенты, остается на совести оценщика (в отчете дело ограничивается одной-двумя фразами). Чтобы убедиться в этом, 5 ЭКО. - 2016. - №9 
достаточно посмотреть любой находящийся в открытом доступе в Интернете отчет об оценке бизнеса ${ }^{7}$.

Вдумчивый читатель легко поймет, что, подбирая в формуле соответствующие взвешивающие коэффициенты, можно получить любой итоговый результат в промежутке между минимальной и максимальной предварительными оценками. Подчеркнем еще раз, что этот весьма субъективный итоговый результат будет соответствовать всем требованиям российского закона и федеральным стандартам оценки.

Можно ли отказаться от произвольной процедуры согласования результатов оценки? Оказывается, можно. Если вообще отказаться от понятия «подход».

Весьма перспективным является применение для определения фундаментальной стоимости добывающей компании модели ЕВО (Edvards-Bell-Ohlson valuation model) $[16,17]$. Суть ее состоит в том, что стоимость компании выражается через сумму её чистых активов и дисконтированного потока доходов, получаемых компанией сверх среднеотраслевой величины (так называемых «остаточных доходов», residual income). Модель сочетает в себе элементы затратного (используется компонента «чистые активы»), доходного (используется компонента «доходы») и сравнительного подходов (учитывается не просто поток доходов, а его отклонение от среднеотраслевого значения). Иначе говоря, данная модель вовсе не обращает внимания на существование неких традиционных подходов, зафиксированных в российском законодательстве.

Любопытно, что согласно модели ЕВО сумма остаточных доходов, в зависимости от высокой или низкой доходности конкретной компании, может быть и положительной, и отрицательной. Таким образом, эта компонента может как увеличивать, так и уменьшать фундаментальную стоимость компании. Этим можно было бы объяснить хроническую «недооцененность» российских сырьевых компаний по сравнению с их аналогами за рубежом. Однако эта гипотеза еще требует серьёзного подтверждения.

\footnotetext{
${ }^{7}$ В качестве одного из примеров приведем ссылку на Отчет об определении рыночной стоимости одной обыкновенной именной акции и одной привилегированной акции ОАО АНК “Башнефть» для определения цены выкупа, размещенный на официальном сайте этой компании. URL: http:// www.bashneft.ru/files/iblock/9a3/9.\%200tchet_rynok_stoimost.pdf (дата обращения: 25.02.2016).
} 


\section{Кому и как продавать?}

Необходимо откровенно признать, что точное определение справедливой цены добывающей компании аналитическими методами при нынешних законодательном и научно-методическом обеспечении, состоянии сырьевых рынков является почти неразрешимой задачей.

С известной долей уверенности можно говорить лишь о нахождении некой минимальной цены, которая может стать отправной точкой для проведения прозрачных конкурсных процедур с привлечением максимально широкого круга потенциальных инвесторов. Должен «по полной программе» включаться объективный рыночный механизм, который координирует решения покупателей и продавцов и который Адам Смит образно называл «невидимой рукой рынка». Уместно привести аналогию с аукционами уникальных произведений искусства, когда начальная цена предмета продажи (наверняка предварительно устанавливаемая опытным оценщиком) в ходе торгов может быть превышена (и по факту превышается) во много раз.

Однако на сегодняшний день намерение государства состоит в том, чтобы, наоборот, сознательно ограничить круг инвесторов. «В результате приватизации государство не должно потерять контроль над стратегически важными предприятиями. ...Контрольный пакет акций системообразующих компаний с госучастием нужно, во всяком случае, сегодня, сохранять в руках государства». «Переход акций в частные руки возможен только при наличии у покупателя стратегии развития приобретаемой компании. ...Новые владельцы приватизируемых активов должны находиться в российской юрисдикции. "Серые" схемы, вывод активов в офшоры, сокрытие собственников долей недопустимы. И конечно, нужно, чтобы будущие инвесторы и приобретатели искали собственные ресурсы либо кредитные ресурсы, но не из государственных банков» [1].

В общем, инвестор должен быть опытным в добыче ископаемых, честным, богатым, умным, дальновидным россиянином, который готов вложить свои собственные деньги и к тому же не рассчитывать на распоряжение своей покупкой. Не поспоришь, сказано всё правильно. Только где найти такого, безупречного во всех отношениях? 
Средства массовой информации, перебирая кандидатуры возможных претендентов на участие в приватизации, сходятся на двух - ПАО «Лукойл» и ОАО «Сургутнефтегаз». Их финансовые ресурсы велики, но не безграничны. На конец сентября 2015 г. на расчетных счетах «Лукойла» было около 4 млрд долл. У компании небольшой чистый долг - 9 млрд долл. У «Сургутнефтегаза» нулевой долг и около 2 трлн руб. ликвидности [18]. Обе компании не подпадают под действие финансовых санкций, объявленных США и ЕС в связи с событиями на Украине, имеют хорошее финансовое состояние и возможность в случае участия в приватизации взять более-менее приличные займы как в России, так и за рубежом.

Получается, что никакой «рыночной» интриги при озвученных требованиях не предвидится. Продавец ясно видит определенного покупателя и понимает его финансовые возможности. Зачем здесь рыночная оценка? Есть опасение, что профессиональный оценщик, «учитывая специфику объекта», будет играть роль статиста, «прикрывающего» уже достигнутые договоренности между продавцом и покупателем. Понимают это и за рубежом: «Таким образом, вновь возникает риск того, что акции будут переданы инсайдерам с хорошими связями» [19].

\section{$\star \star \star$}

Подведем некоторые итоги. Существующие законодательные правила оценки бизнеса создают определенные рамочные ограничения, однако эти рамки настолько широки, что сами по себе никак не могут обеспечить определения «объективной», «честной», «справедливой», «рыночной» цены объекта. Особенностью добывающих компаний является весьма высокая волатильность исходных показателей, необходимых для применения существующих методов оценки, что в свою очередь дает большую вариативность, «субъективность» получаемых числовых оценок их бизнеса.

Требуется большая осторожность при использовании в оценке добывающих компаний показателя текущей рыночной капитализации для определения их фундаментальной стоимости, 
даже если применяются теоретически обоснованные и проверенные на практике методы.

Исправление ошибок итоговой оценки возможно только с привлечением рыночных механизмов продажи, при участии множества независимых и действующих добросовестно потенциальных покупателей. Если нецелесообразно (например, из-за политических причин, экономической ситуации) или невозможно подобрать взаимоприемлемые рыночные способы продажи и «рыночных» инвесторов, с приватизацией добывающих отраслей лучше повременить.

\section{Литература}

1. Стенограмма выступления Президента Российской Федерации на совещании по вопросам приватизации в Кремле 01.02.2016 г. URL: http://kremlin.ru/events/president/news/51249

2. Абрамс Д. Количественная оценка бизнеса. Математический подход для современных профессионалов / Пер. с англ. - М.: Лаборатория Книги, 2014. - 502 с.

3. Алексеев Д. А. Механизмы капитализации компаний. - Иркутск: Изд-во БГУЭП, 2011. - 150 с.

4. Елисеев В. М. Системная технология оценки стоимости крупных производственных комплексов / Отв. ред. проф. М. В. Лычагин. - Новосибирск: ИЭОПП СО РАН, 2004. - 212 с.

5. Коупленд Т. Стоимость компаний: оценка и управление /Т. Коупленд, Т. Коллер, Дж. Муррин; пер. с англ. - М.: Олимп-Бизнес, 2000.

6. Щербаков В. А., Щербакова Н. А. Оценка стоимости предприятия (бизнеса): 4-е изд-е, перераб. и доп. - М.: Изд-во ОМЕГА-Л, 2012. - 315 c.

7. Приказ Минэкономразвития России от 20 мая 2015 г. № 297 «Об утверждении Федерального стандарта оценки "Общие понятия оценки, подходы и требования к проведению оценки (ФСО № 1)"» // КонсультантПлюс: справочно-правовая система. - М., 1992.

8. Приказ Минэкономразвития России от 1 июня 2015 г. № 326 «Об утверждении Федерального стандарта оценки "Оценка бизнеса (ФСО № 8)”»// КонсультантПлюс: справочно-правовая система. - М., 1992.

9. Федеральный закон Российской Федерации от 29.07.1998 г. № 135-Ф3 «Об оценочной деятельности в Российской Федерации» // КонсультантПлюс: справочно-правовая система. - М., 1992. 10. Балабин А. А. Зачем «Газпрому» рыночная капитализация? // ЭКО. - 2015. - № 3. - С. 98-115. 
11. Концептуальные основы финансовой отчетности (Conceptual Framework for Financial Reporting) - пакет руководящих документов, принятых Советом по МСФО в апреле 1989 г., на территории Российской Федерации введен в действие с 9.06.2014 (опубликован на официальном сайте Минфина PФ. URL: http://minfin.ru/common/ upload/library/2014/06/main/kontseptualnye_osnovy_na_sayt_bez_ predisloviya_-_kopiya.pdf

12. Основные направления налоговой политики Российской Федерации на 2016 год и на плановый период 2017 и 2018 годов // КонсультантПлюс: справочно-правовая система. - М., 1992.

13. Фадеева А., Старинская Г. «Снизить добычу вместе»// Ведомости. - 2016. - 27 янв.

14. Папченкова М., Прокопенко А., Фадеева А. Пошлина на нефть стремится к нулю//Ведомости. - 2016. - 23 марта.

15. Щербаков В. А. Аналитический инструментарий процедур оценки стоимости предприятия: проблемы и решения // Настольная книга практикующего оценщика. - Новосибирск: ЦЭРИС, 2013. - C. 230-237.

16. Ohlson J. A. Earnings, Book Values and Dividends in Equity Valuation //Contemporary Accounting Research. - 1995. - Vol. 11. № 2. - P. 661-687. URL: http://www.lingnan.org/cferm/files/earnings, bookvalues, and\%20dividends\%20in\%20equity\%20valuation.PDF 17. Ohlson J. A. Residual Income Valuation: The Problems // Stern School of Business, New York University. - 2000. - Vol. 22. URL: http://ewalsh1.ucd.ie/acctheory/acctheorycourse/lecture2\%20Mats/ ohlson.pdf

18. Фадеева А., Старинская Г. «Лукойл» нашел нефть// Ведомости. - 2016. - 15 фев.

19. Buckley N. Putin's proposals to privatize Russian groups appear badly flaved // Financial Times. - 2016. - 17 feb. URL: http:// www.ft.com/cms/s/0/666589a8-d586-11e5-8887-98e7feb46f27. html\#axzz41RsKxvfy 